\title{
Seleção de populações de Lotus corniculatus L. com maior tolerância ao alumínio em solução nutritiva ${ }^{1}$
}

\author{
Aline Janke ${ }^{2}$, Miguel Dall'Agnol ${ }^{3}$, Armando Martins dos Santos $^{4}$, Carlos Alberto Bissani ${ }^{3}$ \\ 1 Pesquisa financiada pela Coordenação de Aperfeiçoamento de Pessoal de Nível Superior (CAPES). \\ 2 Programa de Pós-graduação em Zootecnia/UFRGS, bolsista CAPES. \\ 3 Universidade Federal do Rio Grande do Sul. \\ ${ }^{4}$ Programa de Pós-graduação em Zootecnia/UFRGS, bolsista CNPq.
}

RESUMO - O experimento foi realizado com o objetivo de selecionar genótipos de Lotus corniculatus L. (Draco, São Gabriel e UFRGS) mais tolerantes ao alumínio, utilizando-se a técnica de seleção em solução nutritiva. A solução continha $200 \mu \mathrm{mol} / \mathrm{L}$ de cálcio $\left(\mathrm{CaCl}_{2}\right), 100 \mu \mathrm{mol} / \mathrm{L}$ de alumínio $\left(\mathrm{AlCl}_{3}\right)$ e $\mathrm{pH}$ controlado na faixa de 4,1 a 4,3. Realizaram-se dois ciclos de seleção, nos quais as plântulas foram selecionadas pelo comprimento final das radículas. Posteriormente, avaliou-se o ganho genético alcançado nos ciclos de seleção, tanto nas populações originais como nas melhoradas, em um experimento com solução nutritiva com quatro concentrações de alumínio $(0,50,100$ e $150 \mu \mathrm{mol} / \mathrm{L})\left(\mathrm{AlCl}_{3}\right)$, por meio do crescimento radicular líquido. O uso de solução nutritiva foi eficiente na seleção de plântulas de cornichão tolerantes ao alumínio. Os materiais analisados apresentam diferenças em relação a esta característica, destacando-se o genótipo UFRGS $\mathrm{F}_{2}$, proveniente de dois ciclos de seleção, como o material com maior tolerância ao alumínio.

Palavras-chave: cornichão, melhoramento, solos ácidos

\section{Selection of populations of Lotus corniculatus L. with increased tolerance to aluminum in nutrient solution}

\begin{abstract}
The experiment was carried out to select genotypes of Lotus corniculatus L. (Draco, São Gabriel and UFRGS) more tolerant to aluminum, using the technique of selection in nutrient solution. The solution contained $200 \mu \mathrm{mol} / \mathrm{L}$ calcium $\left(\mathrm{CaCl}_{2}\right)$ and $100 \mu \mathrm{mol} / \mathrm{L}$ aluminum $\left(\mathrm{AlCl}_{3}\right)$ and a $\mathrm{pH}$ controlled in the range from 4.1 to 4.3. It was performed two cycles of selection, in which the seedlings were selected by the root final length. Subsequently, the genetic gain achieved in the cycles of selection was tested, in original and improved populations in an experiment in nutrient solution with four concentrations of aluminum $(0,50,100$ and $150 \mu \mathrm{mol} / \mathrm{L})\left(\mathrm{AlCl}_{3}\right)$, by liquid root growth. Use of nutritional solution was efficient in the selection of seedlings of birdsfoot trefoil tolerant to aluminum. The materials analyzed differ for this characteristic, with the genotype UFRGS $\mathrm{F}_{2}$, being the most tolerant.
\end{abstract}

Key Words: acid soils, birdsfoot trefoil, improvement

\section{Introdução}

Os solos ácidos são encontrados em grande parte do mundo, principalmente nas regiões tropicais e subtropicais úmidas, onde o volume considerável de chuvas e as temperaturas elevadas acabam acelerando o intemperismo. Nesses solos, o principal fator limitante é a presença de alumínio tóxico $\left(\mathrm{Al}^{3+}\right)$ em elevadas concentrações, que reduz o crescimento e a produtividade das plantas (Delhaize \& Ryan, 1995).

A redução na quantidade de alumínio pode ser realizada por meio de práticas de calagem, pois esse elemento é totalmente neutralizado quando o $\mathrm{pH}$ do solo é superior a
5,5 (Bohnen et al., 2006). Por outro lado, o uso de corretivos representa acréscimo nos custos de produção. Além disso, o alumínio não ocorre apenas na camada arável do solo, mas também em maiores profundidades, tornando difícil a realização dessa operação (Sousa et al., 2007).

Outra forma de superar as dificuldades decorrentes da presença do $\mathrm{Al}^{3+}$ no solo é a utilização de cultivares tolerantes (Foy et al., 1978), obtidos por meio da exploração do potencial genético de cada espécie. O uso desses materiais pode diminuir os custos de implantação e manutenção da cultura e permitir melhor desenvolvimento em situações de estresse hídrico, pois as plantas tolerantes apresentam melhor desenvolvimento do sistema radicular. 
A seleção em solução nutritiva destaca-se entre os métodos existentes por ser relativamente fácil e rápida, além de apresentar baixos custos. Outro fator importante desse método é a escolha dos materiais pela visualização das raízes, pois o principal sintoma de toxidez por alumínio nas plantas é a redução do crescimento radicular (Foy et al., 1978).

O cornichão (Lotus corniculatus L.), uma espécie promissora para utilização em programas de melhoramento, encontra-se amplamente distribuído no mundo, destacando-se pelo seu alto valor nutritivo, pela capacidade de desenvolvimento em diversos ambientes e por não provocar timpanismo (Beuselinck, 1999). Além disso, é capaz de tolerar mais a acidez e a baixa fertilidade do solo em comparação a outras leguminosas de importante valor forrageiro, como o trevobranco (Trifolium repens L.). Entretanto, em razão da elevada concentração de alumínio nos solos do Sul do Brasil, ainda é necessário melhorar essa característica.

Este trabalho foi realizado visando à obtenção de populações de cornichão com maior tolerância ao alumínio por meio da seleção de genótipos em solução nutritiva.

\section{Material e Métodos}

O experimento foi conduzido em casa de vegetação, no Departamento de Plantas Forrageiras e Agrometeorologia (DPFA) da Faculdade de Agronomia da Universidade Federal do Rio Grande do Sul (UFRGS), localizada no município de Porto Alegre, no período de 11 de junho de 2007 a 19 de janeiro de 2009.

A metodologia utilizada, assim como a escolha das concentrações de cálcio e alumínio, para a seleção das plântulas em solução nutritiva foi baseada em um experimento realizado anteriormente com cornichão (Santos et al., 2007).

Foram utilizados inicialmente três genótipos de L. corniculatus: INIA Draco, cultivar comercial originário do Uruguai; São Gabriel, cultivar comercial originário do Brasil; e UFRGS, população experimental desenvolvida pela Faculdade de Agronomia da UFRGS. Esses genótipos constituíram as populações originais Draco (DR), São Gabriel(SG) e UFRGS (UF).

Utilizou-se cerca de 0,60 g de sementes de cada população. As sementes foram previamente tratadas com hipoclorito de sódio a $1 \%$ e escarificadas manualmente com lixa ${ }^{0} 100$. As sementes foram semeadas em caixas plásticas sobre papel-filtro, onde foram umedecidas desde o primeiro dia da semeadura com uma solução de $200 \mu \mathrm{mol} / \mathrm{L}$ de cálcio $\left(\mathrm{CaCl}_{2} \cdot 2 \mathrm{H}_{2} \mathrm{O}\right)$ e $100 \mu \mathrm{mol} / \mathrm{L}$ de alumínio $\left(\mathrm{AlCl}_{3} \cdot 6 \mathrm{H}_{2} \mathrm{O}\right)$ e mantidas em temperatura ambiente, sem inoculantes.
Depois de sete dias, quando as radículas das três populações atingiram cerca de $10 \mathrm{~mm}$ de comprimento, as plântulas que apresentaram uniformidade e normalidade das radículas foram transplantadas para telas plásticas com malha de 1,5 mm de diâmetro coladas sob lâminas de poliestireno expandido (isopor ${ }^{\circledR}$ ), com um $\mathrm{cm}$ de espessura, visando à sustentação das plântulas sobre a solução nutritiva.

Foram utilizadas quatro bandejas, cada uma contendo as três populações originais de cornichão. Em cada bandeja foram transplantadas cerca de 100 plântulas de cada população, totalizando 300 plântulas por bandeja. A solução nutritiva era composta de $200 \mu \mathrm{mol} / \mathrm{L}$ de cálcio $\left(\mathrm{CaCl}_{2} \cdot 2 \mathrm{H}_{2} \mathrm{O}\right)$ e $100 \mu \mathrm{mol} / \mathrm{L}$ de alumínio $\left(\mathrm{AlCl}_{3} \cdot 6 \mathrm{H}_{2} \mathrm{O}\right)$, únicos minerais fornecidos. $\mathrm{O}$ pH da solução foi ajustado para uma faixa de 4,1 a 4,3 comácido clorídrico(HCl), sendo verificado diariamente e ajustado quando necessário. A troca total da solução foi feita a cada três dias para evitar o acúmulo de exsudados e a alteração das concentrações de cálcio e alumínio. Cada bandeja possuía um volume final de solução de 5 litros e foi aerada constantemente com compressores para aquário. A capacidade de aeração dos compressores era de 40 L/hora.

Após as plântulas serem mantidas por 14 dias em solução, foi realizada a seleção das populações originais, considerando-se o maior comprimento radicular, sendo imposta uma pressão de seleção de $10 \%$ em cada população. Portanto, foram selecionadas cerca de 40 plântulas por população, que foram transplantadas para vasos com substrato. As plantas foram conduzidas até a polinização, e cada população cruzada individualmente e manualmente, por um período aproximado de 60 dias.

Durante todo o período experimental, a casa de vegetação recebeu iluminação artificial com o objetivo de estimular e manter o florescimento das plantas. O sistema de iluminação foi realizado com lâmpadas halógenas brancas de $150 \mathrm{~W}$ de potência, que permaneceram ligadas das $6 \mathrm{~h}$ às $22 \mathrm{~h}$.

Os legumes produzidos de cada população foram colhidos e acondicionados em sacos de papel, os quais foram levados à estufa de ventilação forçada, com temperatura entre 28 e $30^{\circ} \mathrm{C}$, por um período de 96 horas. Após a secagem, os legumes foram trilhados e as sementes submetidas a um processo de limpeza visando à eliminação de sementes chochas. A produção de sementes foi determinada, e as mesmas separadas por população e acondicionadas em sacos de papel, sendo mantidas em refrigerador $\left(4^{\circ} \mathrm{C}\right)$ até a sua utilização.

As sementes obtidas pelos cruzamentos nas populações originais constituíram as populações Draco $\mathrm{F}_{1}\left(\mathrm{DR}-\mathrm{F}_{1}\right)$, 
São Gabriel $\mathrm{F}_{1}\left(\mathrm{SG}-\mathrm{F}_{1}\right)$ e UFRGS $\mathrm{F}_{1}\left(\mathrm{UF}-\mathrm{F}_{1}\right)$, as quais passaram pelo segundo ciclo de seleção, pela mesma metodologia utilizada anteriormente, visando aumentar a tolerância ao alumínio. As sementes obtidas do novo ciclo formaram as populações Draco $\mathrm{F}_{2}\left(\mathrm{DR}-\mathrm{F}_{2}\right)$, São Gabriel $\mathrm{F}_{2}$ $\left(\mathrm{SG}-\mathrm{F}_{2}\right)$ e UFRGS $\mathrm{F}_{2}\left(\mathrm{UF}-\mathrm{F}_{2}\right)$. Aproximadamente 40 plântulas foram selecionadas por população em cada um dos ciclos de seleção.

Após a coleta das sementes das populações $F_{2}$, todas as populações selecionadas $\left(F_{1}\right.$ e $\left.F_{2}\right)$ foram testadas em relação ao progresso alcançado, tendo as mesmas sido comparadas com as populações originais em diferentes concentrações de alumínio.

Utilizaram-se cerca de 0,10 g de sementes de cada população de cornichão (DR, SG, UF; DR-F ${ }_{1}, \mathrm{SG}-\mathrm{F}_{1}, \mathrm{UF}-\mathrm{F}_{1}$; DR- $\mathrm{F}_{2}, \mathrm{SG}-\mathrm{F}_{2}$ e UF- $\mathrm{F}_{2}$ ) além de $0,20 \mathrm{~g}$ de sementes de alfafa crioula (Medicago sativa L.), considerada testemunha por ser reconhecida como uma espécie sensível ao alumínio. As sementes foram tratadas com hipoclorito de sódio a $1 \%$, escarificadas manualmente com lixa ${ }^{\circ} 100$ e semeadas em caixas plásticas sobre papel-filtro, onde foram umedecidas com água bidestilada até o transplante para as bandejas.

Sete dias após a semeadura, as plântulas foram transplantadas para telas plásticas com malha de 1,5 mm de diâmetro coladas sob lâminas de isopor de $1 \mathrm{~cm}$ de espessura. Foram preparadas quatro soluções nutritivas, formuladas conforme descrito por Santos et al. (2007) contendo $200 \mu \mathrm{mol} / \mathrm{L}$ de cálcio $\left(\mathrm{CaCl}_{2} \cdot 2 \mathrm{H}_{2} \mathrm{O}\right)$, e quatro concentrações de alumínio: 0, 50,100 e $150 \mu \mathrm{mol} / \mathrm{L}$ de alumínio $\left(\mathrm{AlCl}_{3} \cdot 6 \mathrm{H}_{2} \mathrm{O}\right)$, considerando o nível zero como controle. A solução foi aerada constantemente com compressores para aquário e o $\mathrm{pH}$ foi ajustado diariamente para uma faixa de 4,1 a 4,3 com $\mathrm{HCl}$.

Ao todo, utilizaram-se oito bandejas plásticas contendo 5 litros de solução (duas para cada concentração de alumínio) e seis plântulas de cada população por bandeja, totalizando 12 plântulas de cada população por concentração de alumínio. As plântulas foram conduzidas nas bandejas por um período de 14 dias; a solução nutritiva foi trocada a cada três dias e o pH era verificado diariamente e ajustado quando necessário.

Avaliou-se o crescimento radicular líquido (comprimento final menos comprimento inicial). Os dados foram submetidos à análise estatística com auxílio do software SAS, versão 8.0, pelo procedimento "Factorial ANOVA”, constituindo-se análise de variância fatorial (genótipos $\times$ doses de alumínio), tendo suas médias comparadas pelo teste de Student-Newman-Keuls (SNK) com 5\% de probabilidade, quando houve significância para o teste F. O teste SNK foi escolhido por comparar médias de amplitude variável, sendo capaz de combinar sensibilidade e precisão na detecção de diferenças entre os tratamentos (Steel \& Torrie, 1980).

\section{Resultados e Discussão}

A análise de variância indicou interação significativa $(\mathrm{P}<0,05)$ entre os genótipos testados e as concentrações de alumínio utilizadas (Tabela 1). O crescimento radicular líquido foi semelhante entre todas as populações de cornichão em que foi aplicada a solução sem alumínio, porém foi inferior ao da alfafa. Entretanto, o inverso ocorreu nas populações em que foi aplicada solução com alumínio, pois houve redução acentuada no crescimento radicular líquido da alfafa, desde a concentração $50 \mu \mathrm{mol} / \mathrm{L}$, o que comprova a maior sensibilidade ao alumínio dessa espécie.

Entre os genótipos de cornichão, o crescimento radicular líquido foi semelhante entre as doses 0 e $50 \mu \mathrm{mol} / \mathrm{L}$, com exceção do genótipo Draco, que apresentou maior redução em comparação às demais populações de cornichão e comportamento semelhante ao da alfafa.

Nas concentrações elevadas de alumínio, as populações melhoradas do genótipo UFRGS destacaram-se das originais, de modo que os materiais das gerações $F_{1}$ e $F_{2}$ mantiveram seus crescimentos radiculares líquidos satisfatórios até a concentração de $100 \mu \mathrm{mol} / \mathrm{L}$. No nível $150 \mu \mathrm{mol} / \mathrm{L}$, houve redução significativa no crescimento radicular líquido das populações estudadas, entretanto, numericamente, as populações $F_{2}$ dos genótipos São Gabriel e UFRGS apresentaram os maiores valores. Em contrapartida, os menores valores foram observados nas populações de alfafa e do cultivar Draco.

Tabela 1 - Crescimento radicular líquido (cm) de populações de cornichão e alfafa-crioula em solução nutritiva contendo cálcio e quatro concentrações de alumínio

\begin{tabular}{|c|c|c|c|c|}
\hline \multirow[t]{2}{*}{ População } & \multicolumn{4}{|c|}{ Concentração de alumínio ( $\mu \mathrm{mol} / \mathrm{L})$} \\
\hline & 0 & 50 & 100 & 150 \\
\hline Alfafa & $0,50 \mathrm{~A} * \mathrm{a} * *$ & $0,21 \mathrm{Cb}$ & $0,16 \mathrm{Cbc}$ & $0,11 \mathrm{Bc}$ \\
\hline Draco & $0,30 \mathrm{Ba}$ & $0,22 \mathrm{BCb}$ & 0,19BCb & $0,12 \mathrm{ABC}$ \\
\hline Draco $F_{1}$ & $0,29 \mathrm{Ba}$ & $0,25 \mathrm{ABCab}$ & $0,21 \mathrm{ABCb}$ & $0,12 \mathrm{ABC}$ \\
\hline Draco $F_{2}$ & $0,28 \mathrm{Ba}$ & $0,25 \mathrm{ABCab}$ & $0,21 \mathrm{ABCb}$ & $0,14 \mathrm{ABC}$ \\
\hline São Gabriel & $0,32 \mathrm{Ba}$ & $0,29 \mathrm{ABCa}$ & $0,20 \mathrm{ABCb}$ & $0,15 \mathrm{ABb}$ \\
\hline São Gabriel $\mathrm{F}_{1}$ & $0,32 \mathrm{Ba}$ & $0,32 \mathrm{ABa}$ & $0,27 \mathrm{ABa}$ & $0,16 \mathrm{ABb}$ \\
\hline São Gabriel $\mathrm{F}_{2}$ & $0,34 \mathrm{Ba}$ & 0,31ABCab & $0,28 \mathrm{ABb}$ & $0,18 \mathrm{ABc}$ \\
\hline UFRGS & $0,35 \mathrm{Ba}$ & 0,29ABCab & $0,24 \mathrm{ABCb}$ & $0,15 \mathrm{ABC}$ \\
\hline UFRGS $_{1}$ & $0,32 \mathrm{Ba}$ & 0,30АВСа & $0,28 \mathrm{ABa}$ & $0,16 \mathrm{ABb}$ \\
\hline 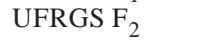 & $0,35 \mathrm{Ba}$ & $0,34 \mathrm{Aa}$ & $0,29 \mathrm{Aa}$ & $0,20 \mathrm{Ab}$ \\
\hline
\end{tabular}

* Médias seguidas de mesma letra maiúscula na coluna, não diferem pelo teste SNK a $5 \%$.

** Médias seguidas de mesma letra minúscula na linha, não diferem pelo teste SNK a $5 \%$. 
A resposta dos materiais de cornichão às soluções de alumínio permitiu caracterizar o genótipo Draco como sensível ao alumínio, enquanto o São Gabriel e o UFRGS mostraram-se mais tolerantes. Santos et al. (2007) já haviam caracterizado os genótipos Draco e UFRGS quanto à resposta ao alumínio e classificaram esses materiais também como sensíveis e tolerantes, respectivamente.

As diferenças entre os genótipos quanto à tolerância ao alumínio podem ser explicadas pela grande variabilidade genética existente no germoplasma de cornichão (Steiner, 1999). Sardaro et al. (2008) analisando 11 populações selvagens de L corniculatus, com o auxílio de marcadores moleculares, observaram grande variabilidade genética dentro e entre as populações estudadas. Soster et al. (2004) encontraram variação fenotípica no cornichão quando avaliaram oito populações do cv São Gabriel, sendo as maiores diferenças em relação ao hábito de crescimento e ao diâmetro da coroa. Maroso \& Scheffer-Basso (2007) também encontraram diferenças na produção de matéria seca entre diferentes cultivares de Lotus spp. Essa variabilidade deve ser explorada em programas de melhoramento visando à obtenção de materiais que possam ser utilizados como parentais, de acordo com as características desejáveis.

A alfafa mostrou-se sensível ao alumínio, pois sofreu inibição média de $68 \%$ no crescimento radicular líquido nas concentrações de alumínio testadas. Por outro lado, os genótipos de cornichão apresentaram maior tolerância, de modo que as populações originais apresentaram redução média de 36\% no crescimento radicular líquido, enquanto nas populações melhoradas $\left(\mathrm{F}_{2}\right)$ essa diminuição foi de $24 \%$ (Figura 1). A utilização das populações melhoradas de cornichão nas áreas de pastagem com solos ácidos possibilitaria reduzir a quantidade de calcário a ser utilizada e diminuir os custos de implantação e manutenção da pastagem sem prejudicar a produção e a persistência.

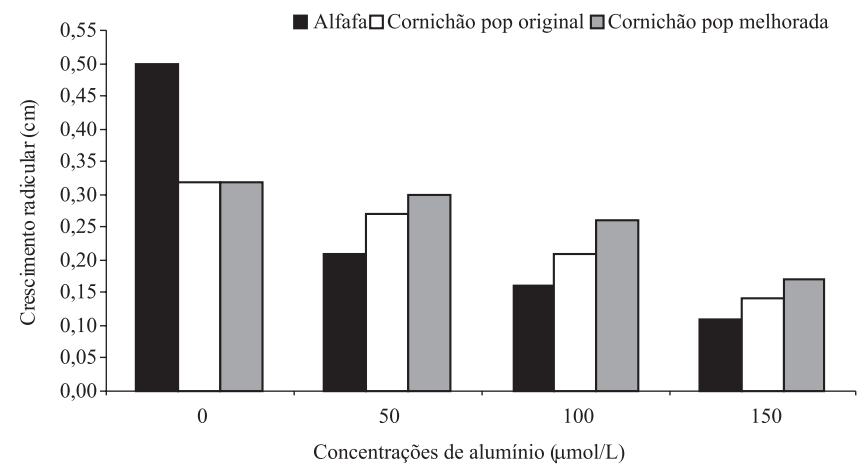

Figura 1 - Crescimento radicular médio (cm) de alfafa-crioula e cornichão em solução nutritiva contendo cálcio e quatro concentrações de alumínio.
Os efeitos da toxidez foram percebidos de maneira proporcional ao aumento das concentrações de $\mathrm{Al}^{3+}$, ocasionando diminuição considerável no crescimento radicular líquido dos genótipos estudados nas doses elevadas. Esses resultados estão de acordo com trabalhos previamente publicados, nos quais a inibição do crescimento radicular foi o sintoma primário de toxidez por alumínio nas plantas (Foy et al., 1978; Delhaize \& Ryan, 1995; Kochian, 1995).

Nos ensaios realizados, as populações melhoradas apresentaram maior crescimento radicular líquido em relação às populações originais, o que confirma que a seleção para tolerância ao alumínio em solução nutritiva simples contendo $100 \mu \mathrm{mol} / \mathrm{L}$ de alumínio e $200 \mu \mathrm{mol} / \mathrm{L}$ de cálcio foi eficiente nos materiais estudados (Figura 2).

Após dois ciclos de seleção, os aumentos percentuais médios no crescimento radicular líquido foram de 6, 14 e 16\% nas populações originais dos genótipos Draco, São Gabriel e UFRGS, respectivamente. Entretanto, como a espécie L. corniculatus é tetraploide, alógama e foram realizados somente dois ciclos de seleção, existe ainda variabilidade genética para a tolerância ao alumínio dentro e entre as populações selecionadas. Além disso, essa variabilidade permite a obtenção de maiores ganhos para essa característica, que pode ser fixada em uma população futura ou combinada com outros atributos relevantes para a espécie.

A tolerância ao alumínio é uma característica herdável e que difere entre as espécies; pode ser regulada por um ou mais genes dominantes ou por vários genes de efeitos aditivos atuantes em diferentes rotas bioquímicas (Kochian, 1995). Ainda não foram divulgados trabalhos que esclareçam como ocorre o controle genético dessa característica no cornichão, o que auxiliaria na escolha do método mais apropriado para a seleção. Apesar disso, Santos et al. (2008) relataram secreção de ácido oxálico em

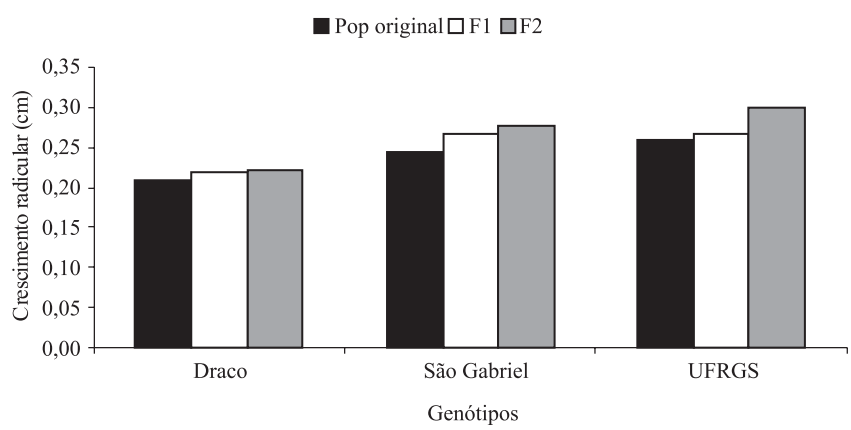

Figura 2 - Tolerância ao alumínio de nove populações de cornichão, avaliada pelo crescimento radicular médio das plântulas. 
genótipos de cornichão quando submetidos a um tratamento com alumínio (200 $\mu \mathrm{mol} / \mathrm{L})$, resposta que indica a liberação de ácidos orgânicos como um dos possíveis mecanismos de tolerância ao $\mathrm{Al}^{3+}$ nesta espécie. Mesmo assim, a seleção recorrente empregada neste trabalho foi eficiente na escolha de plântulas tolerantes ao alumínio.

A variabilidade genética em $L$. corniculatus, assim como a capacidade natural de adaptação a solos pobres e relativamente ácidos (Blumenthal \& McGraw, 1999), deve ser explorada em programas de melhoramento. A busca por materiais tolerantes ao alumínio ocorre em outras culturas de importante valor agronômico, como a alfafa (Caetano, 1998), o sorgo (Caniato et al., 2007), o trevobranco (Voigt \& Staley, 2004) e a soja (Menosso et al., 2000).

A utilização de cultivares capazes de se desenvolver e manter em solos ácidos com o mínimo necessário de calcário é uma alternativa ambiental e economicamente sustentável. O maior comprimento radicular nas plantas tolerantes ao alumínio possibilita a absorção dos nutrientes além da camada arável e permite ainda o acesso à água nas camadas mais profundas durante períodos de déficit hídrico. Do mesmo modo, torna possível a redução dos gastos com correção do solo durante a implantação e/ou manutenção da pastagem.

Ainda assim, os materiais selecionados devem ser testados sob condições de campo para o conhecimento mais aprofundado do comportamento das populações tolerantes em condições reais de utilização.

\section{Conclusões}

A seleção de genótipos de $L$. corniculatus em solução nutritiva contendo $100 \mu \mathrm{mol} / \mathrm{L}$ de alumínio e $200 \mu \mathrm{mol} / \mathrm{L}$ de cálcio é eficiente na obtenção de materiais com maior tolerância ao alumínio. Os materiais de cornichão analisados diferem quanto a essa característica, destacando-se o genótipo Draco como o mais sensível e o UFRGS $F_{2}$, como o mais tolerante.

\section{Referências}

BEUSELINCK, P.R. Trefoil: The science and technology of the Lotus. 28.ed. Madison: CSSA, 1999. 241p.

BLUMENTHAL, M.J.; McGRAW, R.L. Lotus adaptation, use and management. In: BEUSELINCK, P.R. (Ed.) Trefoil: the science and technology of Lotus. Madison: CSSA, 1999. p.97-119. (Special publication, 28).

BOHNEN, H.; MEURER, E.J.; BISSANI, C.A. Solos ácidos e solos afetados por sais. In: MEURER, E.J. (Ed.) Fundamentos de química do solo. 3.ed. Porto Alegre: Genesis, 2006. p.163-180.

CAETANO, J.H.S.; DALL'AGNOL, M.; MEURER, E.J. et al Seleção de alfafa (Medicago sAtiva) para solos ácidos. Revista Científica Rural, v.7, p.6-15, 2002.

CANIATO, F.F.; GUIMARÃES, C.T.; SCHAFFERT, R.E. et al. Genetic diversity for aluminum tolerance in sorghum. Theoretical and Applied Genetics, v.114, n.5, p.863-876, 2007.

DELHAIZE, E.; RYAN, P.R. Aluminum toxicity and tolerance in plants. Plant Physiology, v.107, n.2, p.315-321, 1995.

FOY, C.D.; CHANEY, R.L.; WHITE, M.C. The phiysiology of metal toxicity in plants. Annual Reviews Plant Physiology, v.29, n.1, p.511-566, 1978.

KOCHIAN, L.V. Cellular mechanisms of aluminum toxicity and resistance in plants. Annual Review Plant Physiology, v.46, p.237-260, 1995

MAROSO, R.P.; SCHEFFER-BASSO, S.M. Desenvolvimento morfológico de Lotus spp. de diferentes hábitos de crescimento. Revista Brasileira de Zootecnia, v.36, n.6, p.1961-1968, 2007.

MENOSSO, O.G.; COSTA, J.A.; ANGHINONI, I. et al. Tolerância de genótipos de soja ao alumínio em solução. Pesquisa Agropecuária Brasileira, v.35, n.11, p.2157-2166, 2000.

SANTOS, A.M.; DALL'AGNOL, M.; RAMOS, G.P. et al. Aumento da exudação radicular de ácido oxálico em Lotus corniculatus em resposta a presença de alumínio em solução nutritiva. In: REUNIÓN DEL GRUPO TÉCNICO EM FORRAJERAS DEL CONO SUR, 22., 2008, Minas, Uruguai. Memorias... Montevideo: Tradinco, [2008]. (CD-ROM).

SANTOS, A.M.; DALL'AGNOL, M.; SAWASATO, J.T. et al. Genótipos de cornichão respondem diferentemente à toxidez por alumínio em solução nutritiva. In: CONGRESSO BRASILEIRO DE CIÊNCIA DO SOLO, 31., 2007. Gramado. Anais... Porto Alegre: SBCS, [2007]. (CD-ROM).

SARDARO, M.L.S.; ATALLAH, M.; TAKAVOL, E. et al. Diversity for AFLP and SSR in natural populations of Lotus corniculatus L. from Italy. Crop Science, v.48, p.1080-1089, 2008.

SOSTER, M.T.B.; SCHEFFER-BASSO, S.M.; DALL'AGNOL, M. et al. Caracterização agronômica de genótipos de cornichão (Lotus corniculatus L.). Revista Brasileira de Zootecnia, v.33, n.6, p.1662-1671, 2004.

SOUSA, D.M.G.; MIRANDA, L.N.; OLIVEIRA, S.A. Acidez do solo e sua correção. In: NOVAIS, R.F.; ALVAREZ, V.H.; BARROS, N.F. et al. (Eds.) Fertilidade do solo. Viçosa, MG: Sociedade Brasileira de Ciência do Solo, 2007. p.205-274.

STEINER, J.J. Birdsfoot trefoil origins and germplasm diversity. In: BEUSELINCK, P.R. (Ed.) Trefoil: the science and technology of Lotus. Madison: CSSA, 1999. p.81-96. (Special publication, 28).

STEEL, R.; TORRIE, J. Principles and procedures of statistics. London: McGraw-Hill, 1980. 622p.

VOIGT, P.W.; STALEY, T.E. Selection for aluminum and acidsoil resistance in white clover. Crop Science, v.44, p.38-48, 2004 . 